\title{
Monoaminergic and Kynurenergic Characterization of Frontotemporal Dementia and Amyotrophic Lateral Sclerosis in Cerebrospinal Fluid and Serum
}

\author{
Jana Janssens ${ }^{1,2} \cdot$ Yannick Vermeiren ${ }^{1,2} \cdot$ Martijn van Faassen $^{3} \cdot$ Claude van der Ley $^{3} \cdot$ Ido P. Kema $^{3}$. \\ Peter P. De Deyn ${ }^{1,2,4}$
}

Received: 31 October 2019 / Revised: 30 December 2019 / Accepted: 26 February 2020 / Published online: 4 March 2020

(c) The Author(s) 2020

\begin{abstract}
Exploring the neurochemical continuum between frontotemporal dementia (FTD) and amyotrophic lateral sclerosis (ALS) with respect to monoamines and kynurenines in cerebrospinal fluid (CSF) and serum, may be useful to identify possible new research/therapeutic targets. Hence, we analysed monoamines and kynurenines in CSF and serum derived from patients with FTD $(n=39)$, ALS $(n=23)$, FTD-ALS $(n=4)$ and age-matched control subjects $(n=26)$, using reversed-phase ultra-high performance liquid chromatography (RP-UHPLC) with electrochemical detection (ECD) and liquid chromatography tandem mass spectrometry, respectively. We noted a shared dopaminergic disturbance in FTD and ALS when compared to CONTR, with significantly increased serum DA levels and decreased DOPAC concentrations, as well as decreased DOPAC/DA ratios in both disease groups. In CSF, significantly reduced DOPAC concentrations in FTD and ALS were observed as well. Here, a significant increase in DA levels and decrease in DOPAC/DA ratios was only found in FTD relative to CONTR. With respect to the kynurenine pathway (KP), we only found decreased HK/XA ratios, indicative for vitamin B6 status, in serum of ALS subjects compared to FTD. The dopaminergic commonalities observed in FTD and ALS might relate to a disturbance of dopaminergic nerve terminals in projection areas of the substantia nigra and/or ventral tegmental area, although these findings should first be confirmed in brain tissue. Lastly, based on the results of this work, the KP does not hold promise as a research/therapeutic target in FTD and ALS.
\end{abstract}

Keywords Biomarker $\cdot$ Neuropathology $\cdot$ Dementia $\cdot$ Neurophysiology

Electronic supplementary material The online version of this article (https://doi.org/10.1007/s11064-020-03002-5) contains supplementary material, which is available to authorized users.

Peter P. De Deyn

p.p.de.deyn@umcg.nl

1 Department of Biomedical Sciences, Neurochemistry and Behaviour, Institute Born-Bunge (IBB), University of Antwerp, Wilrijk, Antwerp, Belgium

2 Department of Neurology, Alzheimer Center Groningen, University Medical Center Groningen (UMCG) and University of Groningen, Hanzeplein 1, 9713 GZ Groningen, The Netherlands

3 Department of Laboratory Medicine, University Medical Center Groningen (UMCG) and University of Groningen, Groningen, The Netherlands

$4 \quad$ Faculty of Medicine and Health Sciences, University of Antwerp, Wilrijk, Antwerp, Belgium

\section{Introduction}

Frontotemporal dementia (FTD) and amyotrophic lateral sclerosis (ALS) are devastating neurodegenerative disorders demonstrating genetic and neuropathologic overlap. The most common shared genetic mutation is a GGGGCC expansion in $C 9 O R F 72$, present in approximately $30-47 \%$ $[1,2]$ and $25-34 \%[1,3]$ of familial ALS and FTD cases, respectively. This hexanucleotide expansion is most often associated with the presence of cytoplasmic inclusions containing transactive response DNA-binding protein of $43 \mathrm{kDa}$ (TDP-43) in both diseases [4, 5]. Consequently, these inclusions are found in up to $97 \%$ of ALS and $45 \%$ of FTD cases [6]. Next to the shared genetic and neuropathologic characteristics, similarities in clinical presentation are also observed. Behavioural abnormalities and/or signs of cognitive impairment including executive dysfunction, are observed in $50 \%$ of patients with ALS, while $15 \%$ of these 
subjects reach the diagnostic criteria for FTD [7-10]. Likewise, similar frequencies of motor disturbances are observed in FTD [11, 12].

Although this clinicopathologic overlap has been well covered in the scientific literature, less is known about (monoaminergic) neurotransmitter disturbances in ALS. As this condition is currently treated with strategies primarily targeting glutamatergic neurotransmission and oxidative stress using riluzole and edaravone, respectively [13-15], offering limited benefit, other options based on alternative neurotransmitter systems could be explored. The relative success of selective serotonin reuptake inhibitors (SSRIs) in FTD might point to monoamines as interesting research targets in this disorder, and possibly also in ALS. Furthermore, as previous research demonstrated monoaminergic disturbance in brain tissue (reviewed in [16]) and cerebrospinal fluid (CSF) of FTD patients [17-19], investigating the occurrence of these substances in easily accessible body fluids such as blood, plasma or serum in ALS might be of interest to determine whether FTD and ALS also share neurochemical characteristics.

Due to its implication in (neuro-)inflammation, the kynurenine pathway (KP) has received increasing attention in immune-related diseases such as cancer [20, 21], HIV [22], and several neurodegenerative disorders including ALS [23-25]. Although few researchers have previously focused on determining the KP in samples derived from patients with ALS, it appears that concentrations of some neuroprotective and neurotoxic metabolites are altered in CSF and serum [23, 26]. In FTD, however, little information regarding a possible dysregulation of this metabolic pathway can be found. Given the involvement of the KP in neuroinflammation and since this pathway is linked to the production of 5-HT via their common precursor L-tryptophan (TRP), not only 5-HT and other related monoamines, but also compounds of the KP could possibly represent an interesting means to investigate the neurochemical continuum of FTD-ALS.

\section{Materials and Methods}

\section{Study Population}

This retrospective study used CSF and serum samples derived from the NeuroBioBank of the Institute Born-Bunge (NBB-IBB (no. BB190113), Wilrijk). Monoamines and metabolites were analysed in CSF samples of patients suffering from probable FTD $(n=39)$ [27], FTD-ALS $(n=4)$, suspected, possible and probable ALS $(n=23)$ [28], and age-matched control subjects (CONTR) $(n=26)$. Serum samples were derived from the same patients, although for 3 ALS subjects, no serum samples were available. Patients and control subjects were recruited at the Memory Clinic of the Hospital Network Antwerp (ZNA) Middelheim and Hoge Beuken, as CSF and serum sampling was part of their clinical diagnostic workup. Psychiatric antecedents and central nervous system pathology other than FTD and ALS were regarded as exclusion criteria. Control subjects came to the clinic because of (tension) headache, lumbar canal stenosis, cervicalgia/cervical myelopathy, carpal tunnel syndrome, nausea, chronic gait disorders, periodic fever syndrome, leucopenia, struma simplex, facial arteriovenous malformations, and sinusitis. In patients who gave brain donation consent, brain autopsy was generally performed within $6-8 \mathrm{~h}$ postmortem. The right hemisphere was immersion-fixated in a $12 \%$ formalin solution for neuropathological examination, while the left hemisphere was frozen at $-80^{\circ} \mathrm{C}[29,30]$. In the FTD-ALS group, only one subject had neuropathological confirmation of the initial clinical diagnosis, with molecular lesions classified as TDP-43 Type B. Similarly, only one subject was neuropathologically confirmed as definite ALS. Genetically, 11 FTD subjects had a hexanucleotide expansion in C9ORF72, three patients had a GRN mutation, two subjects had a MAPT mutation and two other patients had a mutation in either $T B K 1$ or VCP. A summary of neuropathologically confirmed cases and related genetics in the FTD group can be found in Fig. 1. This study was approved by the Medical Ethical Committee of the Middelheim General Hospital (Antwerp, Belgium, file numbers 2805 and 2806), and was conducted in line with the Helsinki Declaration.

\section{Sampling Of Cerebrospinal Fluid And Serum}

Lumbar puncture was performed at the L3/L4 or L4/L5 intervertebral space to collect a total volume of $16.5 \mathrm{~mL}$, which was divided across five fractions of $4.5 \mathrm{~mL}, 1.5 \mathrm{~mL}$, $1.5 \mathrm{~mL}, 4.5 \mathrm{~mL}$ and $4.5 \mathrm{~mL}$, respectively, in polypropylene vials (Nalgene; VWR, Leuven, Belgium) [31]. Serum was obtained after total blood sampling into two serum gel

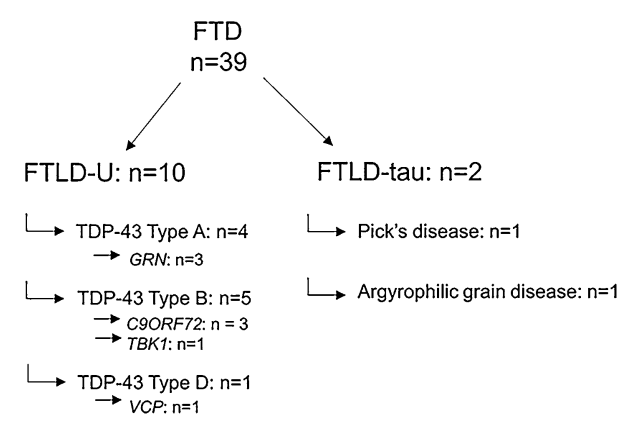

Fig. 1 Overview of neuropathological diagnoses in the FTD group. C9ORF72 chromosome 9 open reading frame 72, FTLD- $U$ frontotemporal lobar degeneration with ubiquitin-positive inclusions, FTD frontotemporal dementia, GRN progranulin gene, TBK1 TANK-binding kinase 1, TDP-43 transactive response DNA-binding protein of $43 \mathrm{kDa}, V C P$ valosin-containing protein 
tubes with clotting activator (S-Monovette $7.5 \mathrm{~mL} \mathrm{Z}$-gel (Sarstedt, Nümbrecht, Germany)), which were centrifuged during $10 \mathrm{~min}$ at $3000 \mathrm{rpm}$. Afterwards, serum was distributed to polypropylene vials. Both CSF and serum samples were frozen and stored at $-80^{\circ} \mathrm{C}$ until analysis.

\section{RP-UHPLC-ECD}

An optimized and validated reversed-phase ultra-highperformance liquid chromatography (RP-UHPLC) system with electrochemical detection (ECD) was used to determine (nor)adrenaline and its metabolite 3-methoxy-4-hydroxyphenylglycol (MHPG), dopamine (DA) and its metabolites 3,4-dihydroxyphenylacetic acid (DOPAC) and homovanillic acid (HVA), as well as 5-HT and its metabolite 5-hydroxyindoleacetic acid (5-HIAA). The sample preparation consisted of a purification on Amicon ${ }^{\circledR}$ Ultra 0.5 Centrifugal Filters (cutoff $3000 \mathrm{Da}$; Millipore, Ireland), which were washed twice beforehand with $450 \mu \mathrm{L}$ buffer while centrifuging $\left(14,000 \times g, 25 \mathrm{~min}, 4^{\circ} \mathrm{C}\right)$. Serum and CSF were brought onto these columns, followed by centrifugation at $4{ }^{\circ} \mathrm{C}$ for $40 \mathrm{~min}$ at $14,000 \times \mathrm{g}$. The resulting CSF filtrate was diluted $1: 2$, and either $1: 7$ or $1: 10$, while the filtered serum was diluted 1:5 and 1:25 or 1:30. This RP-UHPLC system operated at an isocratic flow rate of $75 \mu \mathrm{L} / \mathrm{min}$. The Decade II electrochemical detector was equipped with a thin layered electrochemical VT03 flow cell fitted with a glassy carbon $0.7 \mathrm{~mm}$ working electrode and an in situ $\mathrm{Ag} / \mathrm{AgCl}$ (ISAAC) reference electrode. Samples of $5 \mu \mathrm{L}$ were loaded with an Alexys AS 110 Autosampler. Separation was achieved using a short $15 \mathrm{~cm}$ Acquity Column (BEH C18, $1 \mathrm{~mm}$ diameter, particle size $1.7 \mu \mathrm{m}$; Waters, Etten-Leur, the Netherlands) [32].

\section{LC-MS/MS}

Concentrations of TRP, L-kynurenine (KYN), 3-hydroxykynurenine (HK), anthranilic acid (AA), kynurenic acid, xanthurenic acid (XA), quinolinic acid, picolinic acid, and nicotinic acid, were determined at the department of Laboratory Medicine of the University Medical Center Groningen by liquid chromatography in combination with isotope dilution tandem mass spectrometry (LC-MS/MS) essentially as described by [33]. In short, $100 \mu \mathrm{L}$ of CSF or $50 \mu \mathrm{L}$ of serum was mixed with deuterated or ${ }^{13} \mathrm{C}$-labeled internal standards of the KP compounds under investigation. These mixtures were extracted with Strata X-A 96-well plates with a pore size of $33 \mu \mathrm{m}$ and sorbent mass of $30 \mathrm{mg} / \mathrm{well}$ (Cat. No.: 8E-S123-TGB; Strata-X, Phenomenex, Utrecht, the Netherlands) and eluted with $3 \mathrm{M} \mathrm{HCl}$ in 1-butanol. Finally, $1 \mu \mathrm{L}$ was injected into an Acquity UHPLC (Waters, Etten-Leur, the Netherlands) equipped with a Phenomenex Luna column (Omega C18, $100 \times 2.1 \mathrm{~mm}$, particle size $1.6 \mu \mathrm{m})$, and coupled to a XEVO TQ-S MS/MS system (Waters, EttenLeur, the Netherlands). KYN/TRP ratios were calculated as a measure for TDO and IDO activity [34] and HK/XA ratios as a measure for vitamin $\mathrm{B} 6$ function since the enzyme converting HK to XA, kynurenine aminotransferase II, is pyridoxal phosphate-dependent [35].

\section{Statistics}

One-way ANOVA was applied for continuous demographic parameters such as age and storage time. In case the assumption of homogeneity of variances was violated, Welch's ANOVA was applied. Fisher's Exact tests were applied to investigate the association between categorical variables such as disease category, gender and medication use.

Nonparametric statistics were applied to test inter-group differences of monoamines and kynurenines due to the nonnormal distribution of these parameters in CSF and serum. Kruskal-Wallis analyses were applied as omnibus tests, while post-hoc analyses were performed with Mann-Whitney $U$ statistics. Correction for multiple testing was applied using the Benjamini-Hochberg procedure. The results for the FTD-ALS group are presented solely as median concentrations, as the size of this group was very small and often even reduced to $n=2$ or $n=3$. Therefore, we opted not to include monoaminergic and kynurenergic concentrations of this group in statistical tests for group comparisons. Lastly, Spearman's rank correlation analysis was used to assess the relationship between storage time and concentrations of monoamines and kynurenines. Again, Benjamini-Hochberg corrections were applied to account for multiple testing. All statistical analyses were performed using SPSS version 25.0 for Windows. Figures were created with GraphPad Prism version 6 for Windows (GraphPad Software, La Jolla California USA, www.graphpad.com).

\section{Results}

\section{Demographics}

Table 1 summarizes the demographic details of the study population. Additional information about the types of medication across the different disease groups can be found in Online Resource 1.

\section{Monoamines}

Alterations in the dopaminergic system across disease groups were noted in both $\mathrm{CSF}(\mathrm{H}(2)=9.017, P<0.05$ for DOPAC; $\mathrm{H}(2)=17.963, P<0.001$ for DA; $\mathrm{H}(2)=12.392$, $P<0.05$ for DOPAC/DA and $\mathrm{H}(2)=7.252, P<0.05$ for HVA/DA) and serum $(\mathrm{H}(2)=12.116, P<0.05$ for DOPAC, 
Table 1 Demographics of the study populations for analysis of monoamines and kynurenines

\begin{tabular}{|c|c|c|c|c|c|c|c|}
\hline Parameter & Compounds of interest & Sample type & CONTR & FTD & FTD-ALS & ALS & Test statistic \\
\hline \multirow[t]{4}{*}{ Age at sampling (years) } & \multirow[t]{2}{*}{ Monoamines } & CSF & $\begin{array}{l}67.0 \pm 8.0 \\
\mathrm{n}=26\end{array}$ & $\begin{array}{l}67.4 \pm 11.6 \\
\mathrm{n}=39\end{array}$ & $\begin{array}{l}64.7 \pm 5.7 \\
\mathrm{n}=3\end{array}$ & $\begin{array}{l}67.2 \pm 10.3 \\
\mathrm{n}=23\end{array}$ & $\begin{array}{l}\mathrm{F}(3,87)=0.069 \\
P>0.05\end{array}$ \\
\hline & & Serum & $\begin{array}{l}67.2 \pm 8.3 \\
\mathrm{n}=26\end{array}$ & $\begin{array}{l}67.4 \pm 11.6 \\
\mathrm{n}=39\end{array}$ & $\begin{array}{l}64.7 \pm 5.7 \\
n=3\end{array}$ & $\begin{array}{l}66.9 \pm 10.4 \\
n=20\end{array}$ & $\begin{array}{l}\mathrm{F}(3,84)=0.071 \\
P>0.05\end{array}$ \\
\hline & \multirow[t]{2}{*}{ Kynurenines } & CSF & $\begin{array}{l}67.3 \pm 8.1 \\
\mathrm{n}=25\end{array}$ & $\begin{array}{l}67.4 \pm 11.6 \\
\mathrm{n}=39\end{array}$ & $\begin{array}{l}64.7 \pm 5.7 \\
n=3\end{array}$ & $\begin{array}{l}67.6 \pm 10.5 \\
n=22\end{array}$ & $\begin{array}{l}\mathrm{F}(3,85)=0.071 \\
P>0.05\end{array}$ \\
\hline & & Serum & $\begin{array}{l}67.0 \pm 8.0 \\
\mathrm{n}=26\end{array}$ & $\begin{array}{l}67.4 \pm 11.6 \\
\mathrm{n}=39\end{array}$ & $\begin{array}{l}64.7 \pm 5.7 \\
n=3\end{array}$ & $\begin{array}{l}66.9 \pm 10.4 \\
\mathrm{n}=20\end{array}$ & $\begin{array}{l}\mathrm{F}(3,84)=0.072 \\
P>0.05\end{array}$ \\
\hline \multirow[t]{4}{*}{ Male/female } & \multirow[t]{2}{*}{ Monoamines } & CSF & $14 / 12$ & $20 / 19$ & $1 / 3$ & $21 / 2$ & $\mathrm{FE}=14.2 ; P<0.05$ \\
\hline & & Serum & $14 / 12$ & $20 / 19$ & $1 / 2$ & $18 / 2$ & $\mathrm{FE}=10.9 ; P<0.05$ \\
\hline & \multirow[t]{2}{*}{ Kynurenines } & CSF & $14 / 11$ & $20 / 19$ & $1 / 3$ & $20 / 2$ & $\mathrm{FE}=13.1 ; P<0.05$ \\
\hline & & Serum & $14 / 12$ & $20 / 19$ & $1 / 2$ & $18 / 2$ & $\mathrm{FE}=10.9 ; P<0.05$ \\
\hline \multirow[t]{4}{*}{$\begin{array}{l}\text { Taking/not taking medi- } \\
\text { cation }\end{array}$} & \multirow[t]{2}{*}{ Monoamines } & CSF & $9 / 7$ & $27 / 7$ & $0 / 1$ & $11 / 6$ & $\begin{array}{l}\mathrm{FE}=5.2 \\
P>0.05\end{array}$ \\
\hline & & Serum & $10 / 6$ & $27 / 7$ & $0 / 1$ & $11 / 5$ & $\begin{array}{l}\mathrm{FE}=4.1 \\
P>0.05\end{array}$ \\
\hline & \multirow[t]{2}{*}{ Kynurenines } & CSF & $9 / 7$ & $27 / 7$ & $0 / 1$ & $11 / 6$ & $\begin{array}{l}\mathrm{FE}=5.2 \\
P>0.05\end{array}$ \\
\hline & & Serum & $9 / 7$ & $27 / 7$ & $0 / 1$ & $11 / 5$ & $\begin{array}{l}\mathrm{FE}=5.1 \\
P>0.05\end{array}$ \\
\hline \multirow[t]{4}{*}{ Storage time (months) } & \multirow[t]{2}{*}{ Monoamines } & CSF & $\begin{array}{l}202.5 \pm 30.6 \\
n=26\end{array}$ & $\begin{array}{l}132.8 \pm 62.1 \\
n=39\end{array}$ & $\begin{array}{l}158.3 \pm 44.4 \\
n=3\end{array}$ & $\begin{array}{l}171.9 \pm 76.2 \\
n=23\end{array}$ & $\begin{array}{l}\text { Welch }=10.930 \\
P<0.05\end{array}$ \\
\hline & & Serum & $\begin{array}{l}203.0 \pm 30.6 \\
n=26\end{array}$ & $\begin{array}{l}133.2 \pm 62.2 \\
n=39\end{array}$ & $\begin{array}{l}158.3 \pm 44.4 \\
n=3\end{array}$ & $\begin{array}{l}187.3 \pm 68.2 \\
n=20\end{array}$ & $\begin{array}{l}\text { Welch }=10.848 \\
P<0.05\end{array}$ \\
\hline & \multirow[t]{2}{*}{ Kynurenines } & CSF & $\begin{array}{l}213.0 \pm 30.8 \\
n=25\end{array}$ & $\begin{array}{l}144.6 \pm 62.2 \\
n=39\end{array}$ & $\begin{array}{l}169.7 \pm 44.2 \\
n=3\end{array}$ & $\begin{array}{l}185.9 \pm 77.3 \\
n=22\end{array}$ & $\begin{array}{l}\text { Welch }=10.285 \\
P<0.05\end{array}$ \\
\hline & & Serum & $\begin{array}{l}214.2 \pm 30.7 \\
n=26\end{array}$ & $\begin{array}{l}144.6 \pm 62.1 \\
n=39\end{array}$ & $\begin{array}{l}169.7 \pm 44.2 \\
n=3\end{array}$ & $\begin{array}{l}198.8 \pm 68.0 \\
n=20\end{array}$ & $\begin{array}{l}\text { Welch }=10.760 \\
P<0.05\end{array}$ \\
\hline
\end{tabular}

Data regarding age at sampling and sampling time are represented as mean \pm standard deviation. For the numbers of subjects taking/not taking medication, psychotropic substances, riluzole and dietary vitamin B supplements were taken into account

$A L S$ amyotrophic lateral sclerosis, CONTR control, CSF cerebrospinal fluid, FE Fisher's Exact, FTD frontotemporal dementia, FTD-ALS frontotemporal dementia-amyotrophic lateral sclerosis

$\mathrm{H}(2)=16.850, P<0.001$ for $\mathrm{DA}$; and $\mathrm{H}(2)=19.438$, $P<0.0001$ for DOPAC/DA). A general decrease in DOPAC values was observed in FTD and ALS subjects compared to the CONTR group. Increased DA concentrations in CSF were found in the FTD versus the CONTR and ALS groups. In serum, DA levels were also highly significantly increased in the FTD subjects compared to CONTR individuals, while a similar result was observed between the CONTR and ALS group. Analysis of the DOPAC/DA ratio revealed a disturbed dopaminergic catabolism in FTD versus the CONTR group, evidenced by significantly lower CSF and serum DOPAC/DA ratios in the former category. Furthermore, serum DOPAC/DA ratios were severely decreased in ALS subjects compared to healthy CONTR subjects (Fig. 2). Another index of DA catabolism, CSF HVA/DA, was also significantly decreased in FTD compared to CONTR subjects (Fig. 3).

Finally, CSF MHPG differed across diagnostic categories $(\mathrm{H}(2)=8.833, P<0.05)$, with significant differences after post-hoc correction indicating higher MHPG levels in FTD and ALS compared to the CONTR group (Fig. 4). All results of post-hoc comparisons are depicted in Online Resource 2.

\section{Kynurenines}

No statistically significant differences were found after Kruskal-Wallis analysis for individual compounds belonging to the KP, except for CSF TRP $(\mathrm{H}(2)=6.088, P<0.05)$, however, intergroup comparisons for CSF TRP with posthoc Mann-Whitney $U$ tests did not remain significant following Benjamini-Hochberg corrections for multiple comparisons (Fig. 5). We also found a difference in serum HK/XA ratios across diagnostic categories $(\mathrm{H}(2)=8.548$, $P<0.05)$, with lower serum HK/XA ratios in the ALS versus the FTD group (Fig. 6). Post-hoc statistics, in addition to median values for HK/XA in each group, are summarized in Online Resource 2. 
CSF
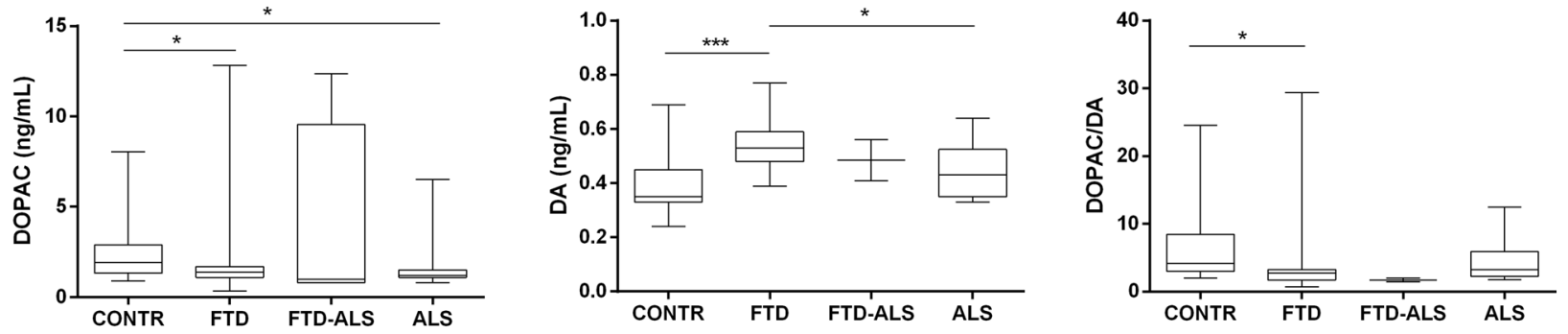

\section{Serum}
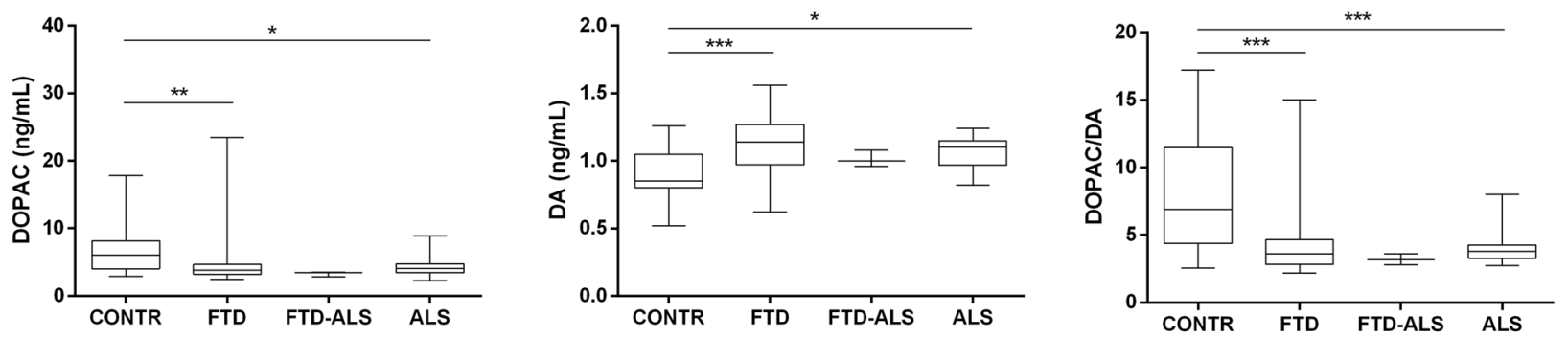

Fig. 2 Dopaminergic findings across diagnostic categories. Data are represented as box- and whisker plots with minimum-maximum ranges. Statistically significant differences after Mann-Whitney $U$ tests with Benjamini-Hochberg post-hoc corrections are depicted by one, two or three asterisks if $P \leq 0.05,0.001$, or 0.0001 , respectively. Sample sizes for CSF DOPAC are: CONTR: $n=26$, FTD: $n=39$, FTD-ALS: $n=4$, ALS: $n=23$, sample sizes for CSF DA and DOPAC/DA are CONTR: $n=21$, FTD: $n=35$, FTD-ALS: $n=2$,
ALS: $n=17$. Sample sizes for serum DOPAC are: CONTR: $n=26$, FTD: $n=39$, FTD-ALS: $n=3$, ALS: $n=20$, sample sizes for serum DA and DOPAC/DA are: CONTR: $n=26$, FTD: $n=35$, FTD-ALS: $\mathrm{n}=3$, ALS: $\mathrm{n}=20$. The FTD-ALS group was not included in the statistical analysis. ALS amyotrophic lateral sclerosis, CONTR control, $C S F$ cerebrospinal fluid, DA dopamine, DOPAC 3,4-dihydroxyphenylacetic acid, FTD frontotemporal dementia, FTD-ALS frontotemporal dementia - amyotrophic lateral sclerosis

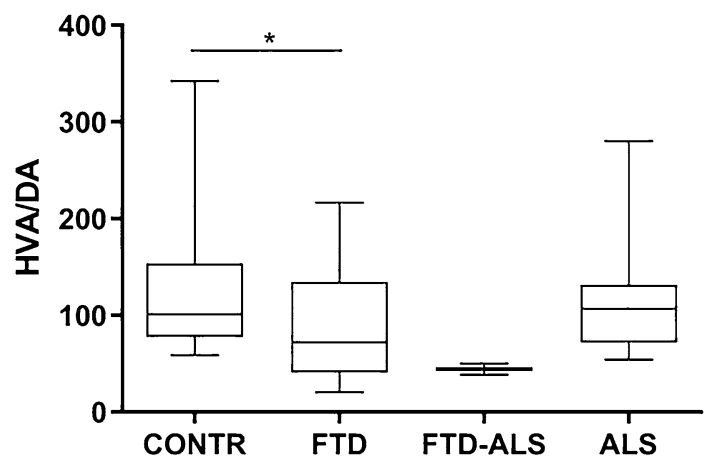

Fig. 3 CSF HVA/DA ratios across diagnostic categories. Data are represented as box- and whisker plots with minimum-maximum ranges. Statistically significant differences after Mann-Whitney $U$ analyses with Benjamini-Hochberg corrections are indicated by an asterisk $(P<0.05)$. Sample sizes for CSF HVA/DA are: CONTR: $\mathrm{n}=21$, FTD: $\mathrm{n}=35$, FTD-ALS: $\mathrm{n}=2$, ALS: $\mathrm{n}=17$. The FTD-ALS group was not included in the statistical analysis. $A L S$ amyotrophic lateral sclerosis, CONTR control, CSF cerebrospinal fluid, DA dopamine, FTD frontotemporal dementia, $F T D-A L S$ frontotemporal dementia-amyotrophic lateral sclerosis, $H V A$ homovanillic acid

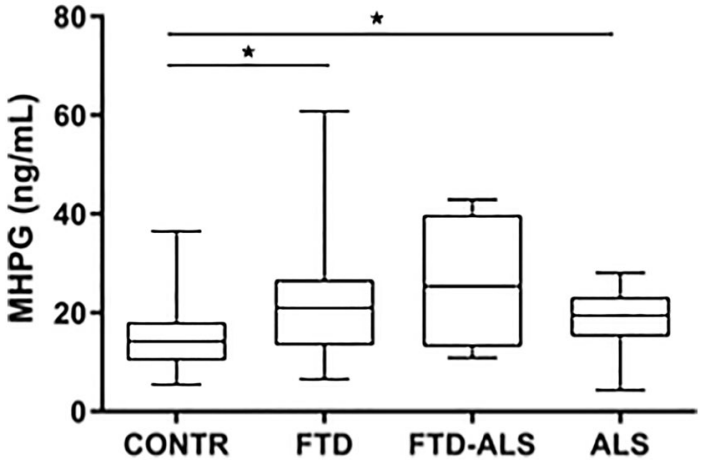

Fig. 4 CSF MHPG levels across diagnostic categories. Data are represented as box- and whisker plots with minimum-maximum ranges. Statistically significant differences after Mann-Whitney $U$ analyses with Benjamini-Hochberg corrections are indicated by an asterisk $(P<0.05)$. Sample sizes for CSF MHPG are: CONTR: $n=26$, FTD $=39$, FTD-ALS: $\mathrm{n}=4$, ALS: $\mathrm{n}=23$. The FTD-ALS group was not included in the statistical analysis. $A L S$ amyotrophic lateral sclerosis, CONTR control, CSF cerebrospinal fluid, FTD frontotemporal dementia, FTD-ALS frontotemporal dementia-amyotrophic lateral sclerosis, MHPG 3-methoxy-4-hydroxyphenylglycol 
A

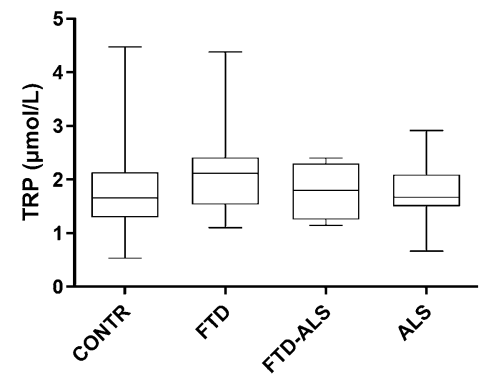

D

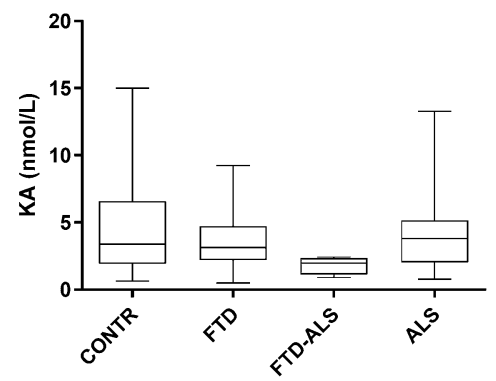

G

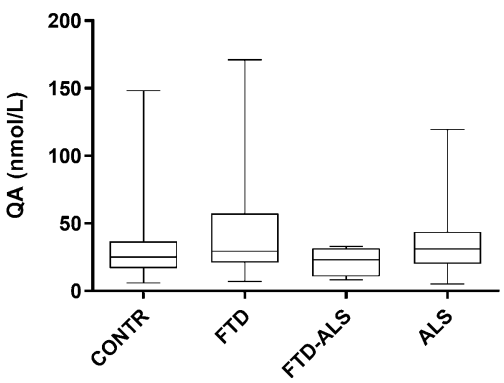

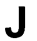

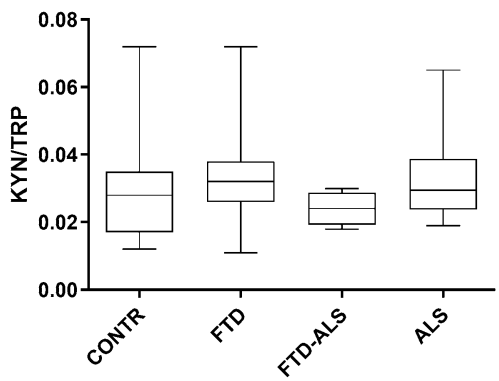

B

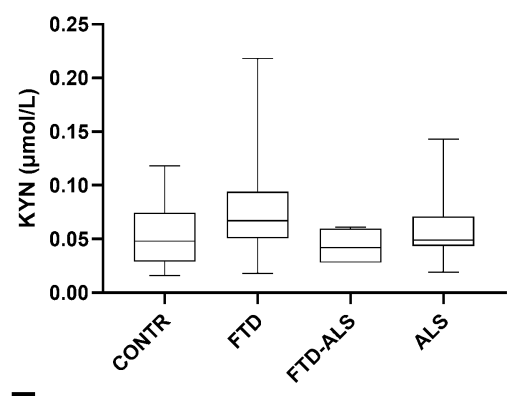

E

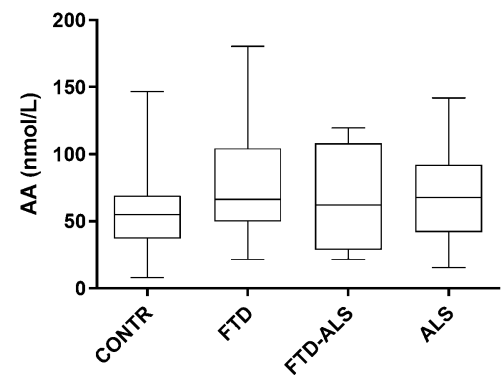

H

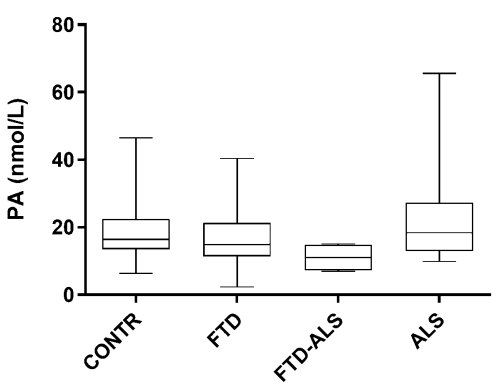

K

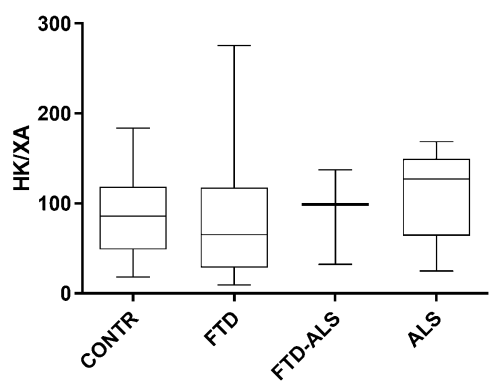

C

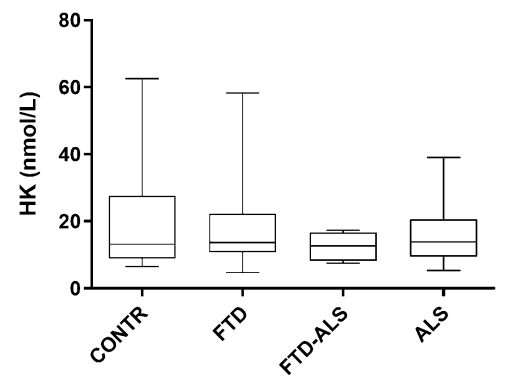

$\mathbf{F}$

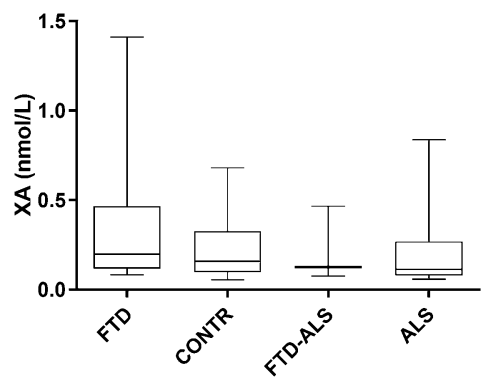

I

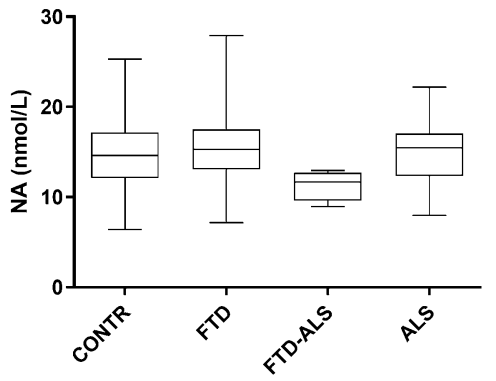

Fig. 5 The KP in CSF. Data are represented as box- and whisker plots with minimum-maximum ranges. Statistically significant differences after Mann-Whitney $U$ analyses with Benjamini-Hochberg corrections are indicated by an asterisk $(P<0.05)$. Sample sizes for TRP are: CONTR: $n=23$, FTD: $n=37$, FTD-ALS: $n=4$, ALS: $n=20$, sample sizes for KYN are: CONTR: $n=21$, FTD: $n=37$, FTD-ALS: $n=4$, ALS: $n=21$, sample sizes for HK are: CONTR: $n=24$, FTD: $\mathrm{n}=36$, FTD-ALS: $\mathrm{n}=4$, ALS: $\mathrm{n}=21$, sample sizes for KA are: CONTR: $n=25$, FTD: $n=39$, FTD-ALS: $n=4$, ALS: $n=22$, sample sizes for AA are: CONTR: $n=24$, FTD: $n=39$, FTD-ALS: $n=4$, ALS: $n=22$, sample sizes for XA are: CONTR: $n=17$, FTD: $n=30$, FTD-ALS: $n=3$, ALS: $n=18$, sample sizes for QA are: CONTR: $\mathrm{n}=23$, FTD: $\mathrm{n}=37$, FTD-ALS: $\mathrm{n}=4$, ALS: $\mathrm{n}=21$, sample sizes for PA are: CONTR: $n=24$, FTD: $n=39$, FTD-ALS: $n=4$, ALS: $n=22$, sample sizes for NA are: CONTR: $n=25$, FTD: $n=39$, FTD-ALS: $n=4$, ALS: $n=22$, sample sizes for KYN/TRP are: CONTR: $n=21$, FTD: $n=35$, FTD-ALS: $n=4$, ALS: $n=20$, sample sizes for HK/XA are: CONTR: $\mathrm{n}=15$, FTD: $\mathrm{n}=30$, FTD-ALS: $\mathrm{n}=3$, ALS: $\mathrm{n}=18$. $A A$ anthranilic acid; $A L S$ amyotrophic lateral sclerosis, CONTR control, CSF cerebrospinal fluid, FTD frontotemporal dementia, FTD-ALS frontotemporal dementia-amyotrophic lateral sclerosis, $H K$ 3-hydroxykynurenine, $K A$ kynurenic acid, $K P$ kynurenine pathway, $K Y N$ L-kynurenine, $N A$ nicotinic acid, $P A$ picolinic acid, $Q A$ quinolinic acid, TRP L-tryptophan, $X A$ xanthurenic acid 
A

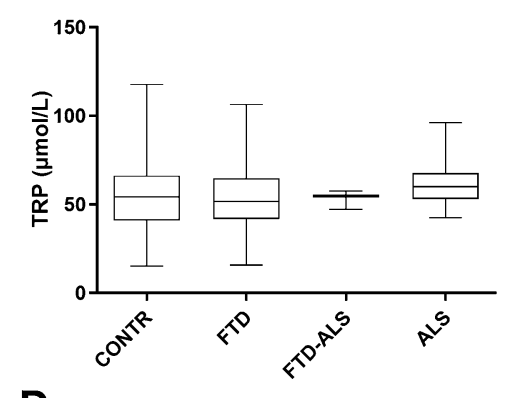

D

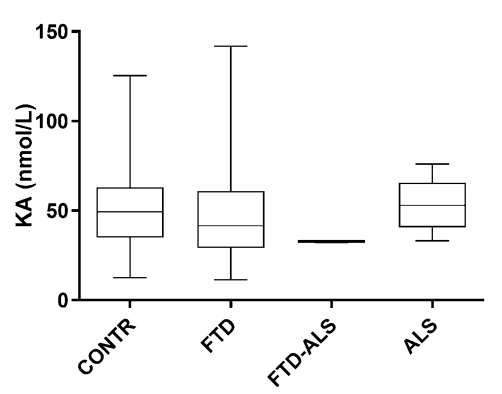

G

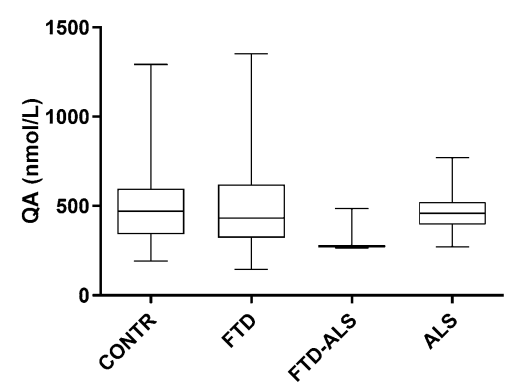

J

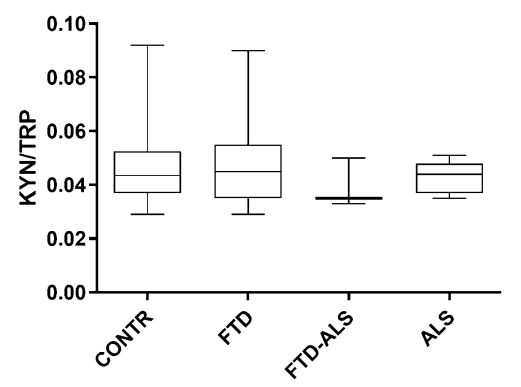

B

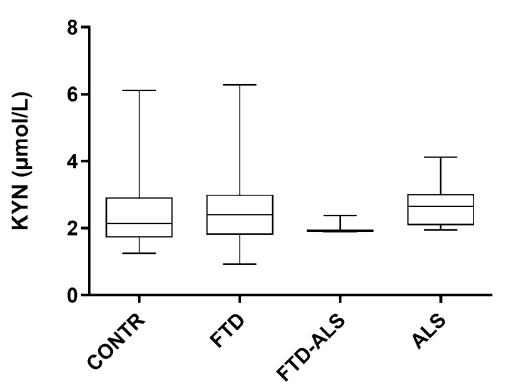

E

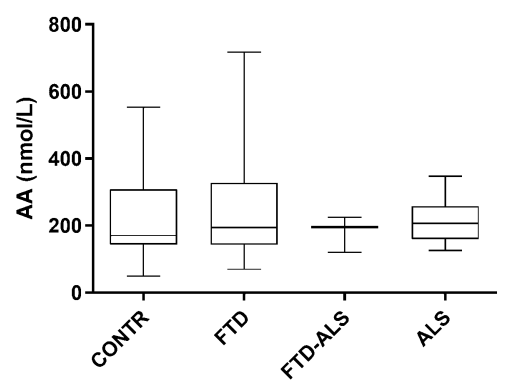

H

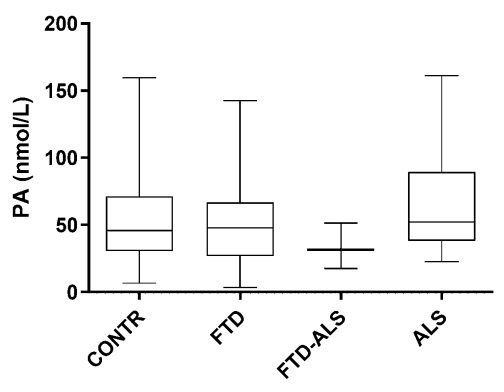

K

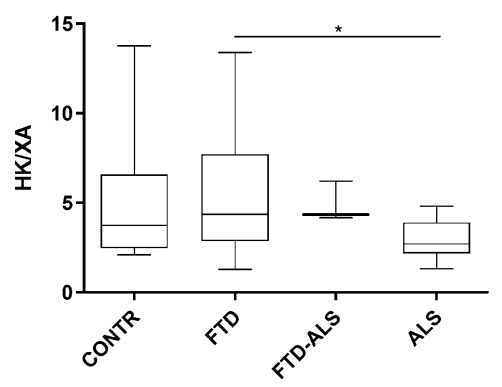

C

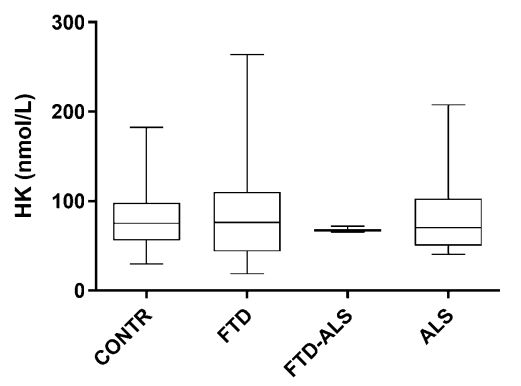

$\mathbf{F}$

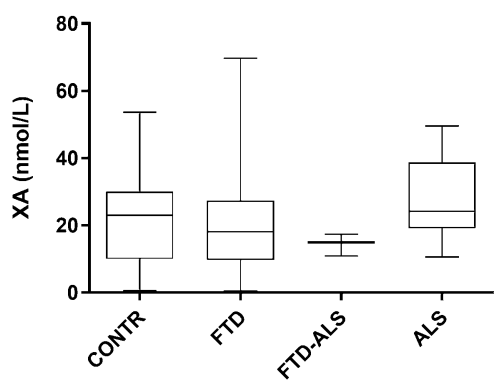

I

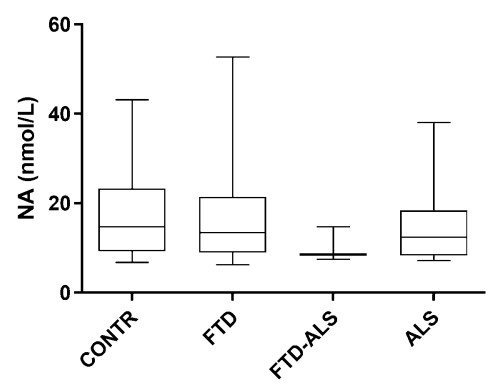

Fig. 6 The KP in serum. Data are represented as box- and whisker plots with minimum-maximum ranges. Statistically significant differences after Mann-Whitney $U$ analyses with Benjamini-Hochberg corrections are indicated by an asterisk $(P<0.05)$. Sample sizes for TRP are: CONTR: $n=26$, FTD: $n=39$, FTD-ALS: $n=3$, ALS: $\mathrm{n}=20$, sample sizes for KYN are: CONTR: $n=26$, FTD: $n=39$, FTD-ALS: $n=3$, ALS: $n=20$, sample sizes for HK are: CONTR: $\mathrm{n}=24$, FTD: $\mathrm{n}=39$, FTD-ALS: $\mathrm{n}=3$, ALS: $\mathrm{n}=19$, sample sizes for KA are: CONTR: $n=26$, FTD: $n=39$, FTD-ALS: $n=3$, ALS: $n=20$, sample sizes for AA are: CONTR: $n=26$, FTD: $n=38$, FTD-
ALS: $n=3$, ALS: $n=20$, sample sizes for XA are: CONTR: $n=25$, FTD: $n=39$, FTD-ALS: $\mathrm{n}=3$, ALS: $\mathrm{n}=20$, sample sizes for QA are: CONTR: $n=25$, FTD: $n=37$, FTD-ALS: $n=3$, ALS: $n=18$, sample sizes for PA are: CONTR: $n=25$, FTD: $n=39$, FTD-ALS: $n=3$, ALS: $n=20$, sample sizes for NA are: CONTR: $n=24$, FTD: $n=38$, FTD-ALS: $n=3$, ALS: $n=20$, sample sizes for KYN/TRP are: CONTR: $n=26$, FTD: $n=39$, FTD-ALS: $n=3$, ALS: $n=19$, sample sizes for HK/XA are: CONTR: $n=22$, FTD: $n=38$, FTD-ALS: $n=3$, ALS: $\mathrm{n}=18$ 


\section{Influence of Psychotropic Medication and Storage Time}

When equivalent analyses were performed to detect differences in monoamine/kynurenine content only in subjects who were free of psychotropic medication and who did not take riluzole nor supplements containing vitamin B, a trend for increased CSF DA levels in FTD and ALS compared to CONTR could be observed $(\mathrm{H}(2)=5.751, P=0.056)$, but none of the monoaminergic differences remained statistically significant. In contrast, a significant difference was found for CSF TRP across groups $(\mathrm{H}(2)=6.548, P<0.05)$.

We found that CSF MHPG and DA were negatively correlated with storage time $(\operatorname{rs}(89)=-0.409, P<0.0001$ and $\operatorname{rs}(73)=-0.330, P<0.05)$, whereas a positive association between storage time and 5-HIAA $(\operatorname{rs}(89)=0.286$, $P<0.05)$ as well as 5-HIAA/5-HT ratios $(\operatorname{rs}(87)=0.346$, $P \leq 0.001)$ was noted. In serum, negative correlations were noted between DA levels and storage time $(\operatorname{rs}(82)=-0.242$, $P<0.05)$ ). As for kynurenines, CSF TRP and serum $\mathrm{HK} / \mathrm{XA}$ ratios decreased with increasing storage time $(\mathrm{rs}(81)=-0.232, P<0.05$ and $\operatorname{rs}(81)=-0.241, P<0.05$, respectively).

\section{Discussion}

\section{Monoamines}

A general dopaminergic disturbance was noted in FTD and ALS compared to CONTR subjects, largely corresponding to previous reports. Single photon emission computed tomography has shown decreased frontal uptake of a dopamine 2 receptor (D2) postsynaptic ligand, as well as a relative frontal hypoperfusion in FTD versus CONTR and subjects with Alzheimer's disease [36]. Reduced uptake of ${ }^{11} \mathrm{C}-2 \beta$ carbomethoxy-3 $\beta$-(4-fluorophenyl) tropane ( $\left.{ }^{11} \mathrm{C}-\mathrm{CFT}\right)$, a cocaine analogue targeting DA transporters (DAT), in the putamen of FTD subjects was also observed in another study [37]. In addition, ALS subjects showed decreased striatal binding of ${ }^{123} \mathrm{I}-\mathrm{N}$-(3-iodopropen-2-yl)-2 $\beta$-carbomethoxy$3 \beta$-(4-chlorophenyl)-tropane $\left({ }^{123} \mathrm{IPT}\right)$, a cocaine analogue binding specifically to DATs [38]. Furthermore, increased DA levels and decreased HVA/DA ratios were observed in Brodmann area (BA)46 and BA6 of FTD subjects compared to CONTR [29]. Taken together, these findings may all indicate disrupted dopaminergic nerve terminals in projection areas of the substantia nigra (SN) and ventral tegmental area (VTA). Reduced presynaptic uptake of ${ }^{123}$ IPT and decreased binding of ${ }^{11} \mathrm{C}-\mathrm{CFT}$ in ALS and FTD, might reflect a dysfunction of dopaminergic nerve terminals, possibly related to presynaptic reuptake mechanisms mediated by DAT. This might explain our observation of increased CSF DA levels in these disease groups. The decreased DOPAC concentrations and DOPAC/DA ratios may then be a result of impaired DOPAC synthesis due to dopaminergic neuron dysfunction. Exploring the observed dopaminergic alterations in brain tissue of FTD and ALS subjects is mandatory to assess the validity of this hypothesis.

It would also be interesting to compare the dopaminergic disturbance in the FTD-ALS continuum with that observed in Parkinson's disease (PD). In a previous study on dopaminergic alterations in CSF of synucleinopathy patients [39], among which PD, dopaminergic data of the PD group were reduced to eliminate influences of dopaminergic medication, resulting in a PD group $(n=17)$ in which only $P D$ patients with CSF and plasma L-DOPA values $\leq 5 \mathrm{nmol} / \mathrm{L}$ and $10 \mathrm{nmol} / \mathrm{L}$, were included. We calculated $\mathrm{DA}$ ratios and DOPAC ratios in CSF for the disease groups included in our study versus the control group (CONTR), as well as identical ratios for the $\mathrm{PD}$ group versus CONTR in the previous report [39]. We observed that the ratios of DOPAC in the FTD, FTD-ALS and ALS groups versus CONTR were 0.7, 0.5 and 0.6, respectively, while this ratio was 0.4 if the DOPAC concentrations of the PD group were normalized to CONTR. For DA, we noted ratios of 1.3 in both FTD as well as FTDALS groups, and 1.0 in ALS compared to CONTR. In the study on catecholaminergic alterations in synucleinopathy subjects [39], the PD/CONTR ratio for DA was 0.8 .

In this respect, it is clear that the extent of the dopaminergic disturbance is most evident in PD, with severely decreased CSF DOPAC and DA concentrations compared to CONTR. This finding of lowered CSF DOPAC and DA concentrations in PD are supported by several other studies [40, 41], even though the sample sizes of these studies were rather small ( $n=4$ and $n=7$, respectively). It is interesting to note that we did not find decreased DA concentrations in FTD or ALS, possibly reflecting a distinct disease mechanism from $\mathrm{PD}$.

The dopaminergic alterations in serum of FTD and ALS versus CONTR subjects resembled those in CSF, which is surprising since DA nor DOPAC readily cross the blood-brain barrier (BBB) [42, 43]. However, several studies have demonstrated impaired BBB integrity in FTD and ALS [44, 45], which might account for the similarities observed in CSF and serum.

The use of psychotropic medication may have influenced our findings since the dopaminergic alterations could not be detected between FTD, ALS or CONTR in a medication-free subgroup. However, given the low number of observations in this analysis ( $n=3-9$ per group), type II errors cannot be ruled out.

The longer storage time in the CONTR group might have led to a false positive result regarding the increased MHPG and DA levels in FTD compared to the CONTR group. Thus, the absolute DA levels in CSF should be considered 
carefully, while the DOPAC concentrations and the dopaminergic turnover in CSF remain unaffected by storage time.

Based on the therapeutic strategies applied in FTD, we expected to find serotonergic (dis)similarities, in the ALSFTD continuum. However, our results suggest a shared dopaminergic disturbance in CSF and serum, except for CSF DA levels. This finding may shift the research in these neurodegenerative conditions to DA-based approaches.

\section{Kynurenines}

In previous studies investigating the KP in ALS, KYN levels, neuroprotective and neurotoxic KP compounds appeared to be altered in this condition [23,26]. It is possible we could not reproduce these findings because of differences in CSF handling, alternative analytical conditions, or distinct demographics. Since the study of Chen et al. included nonage-matched CONTR and ALS groups (average age of 36 and 58 years, respectively) and since the KP is involved in aging, these results, particularly with respect to CSF KYN [46], KYN/TRP ratios as a measure for IDO-activity, and concentrations of QA [47] could also be explained by the higher average age in the ALS group.

The results of subjects who did not take psychotropic medication, riluzole or vitamin B supplements did indicate altered CSF TRP levels between FTD, ALS and CONTR. It is difficult to speculate about the (patho)physiological meaning of this result, as lowered KYN/TRP ratios would indicate a downregulation of IDO/TDO activity, but no such results could be observed. In addition, no serotonergic differences were observed in FTD and ALS versus the CONTR group, indicating that TRP metabolism was not shifted towards the synthesis of serotonergic compounds in these groups. Lastly, our observation of decreased serum HK/XA ratios in ALS compared to FTD could have been influenced by storage time. Another compound of the KP for which we found significant differences, CSF TRP, was also influenced by storage time. Based on the results of this study, we suggest that the KP offers limited therapeutic value/research potential for the FTD-ALS continuum.

\section{Future Perspectives}

Although the SN was shown to be affected in FTD and ALS $[48,49]$, the differential pathology in the SN and/or VTA of FTD and ALS patients does not represent a well-studied topic. It would be interesting to investigate the correlation between neuropathological observations in the SN and VTA, and dopaminergic disturbance in their projection areas in postmortem brain tissue. Alternatively, resting state functional MRI may be applied to assess the functional connectivity between midbrain dopaminergic centers and (pre) frontal cortical regions, combined with CSF sampling in
FTD and ALS subjects. Follow-up of these patients may then result in a better understanding of dopaminergic disturbance, and how this is reflected in bodily fluids. In addition, we recommend the analysis of CSF and serum on a clinically better characterized population, certainly with respect to the ALS group.

In conclusion, we found that ALS and FTD share a dopaminergic disturbance in serum, while these changes are also partly present in CSF. This could possibly be caused by dopaminergic terminal dysfunction in (cortical) projection areas of the SN and VTA. The compounds of the KP did not appear to be altered in FTD or ALS.

Acknowledgements This research was supported by the Alzheimer Research Foundation Belgium (SAO-FRA) under Grant ID20180027; the Methusalem excellence grant of the Flemish Government; the agreement between Institute Born-Bunge and University of Antwerp; the Medical Research Foundation Antwerp; the Thomas Riellaerts research fund; Neurosearch Antwerp; and the Alzheimer Center of the University Medical Center Groningen. Y. Vermeiren is a senior postdoctoral research fellow of VITO-FWO (\#12Z1620N).

Author Contributions Conceptualization: YV, PPDD; Methodology: JJ, YV, MVF, CVDL, IPK; Formal analysis and investigation: JJ, YV, MVF, CVDL; Writing—original draft preparation: JJ; Writing—review and editing: YV, MVF, CVDL, IPK, PPDD; Funding acquisition: YV, PPDD; Resources: YV, MVF, CVDL, IPK, PPDD; Supervision: PPDD.

\section{Compliance with Ethical Standards}

Conflict of interest The authors report no conflict of interest.

Open Access This article is licensed under a Creative Commons Attribution 4.0 International License, which permits use, sharing, adaptation, distribution and reproduction in any medium or format, as long as you give appropriate credit to the original author(s) and the source, provide a link to the Creative Commons licence, and indicate if changes were made. The images or other third party material in this article are included in the article's Creative Commons licence, unless indicated otherwise in a credit line to the material. If material is not included in the article's Creative Commons licence and your intended use is not permitted by statutory regulation or exceeds the permitted use, you will need to obtain permission directly from the copyright holder. To view a copy of this licence, visit http://creativecommons.org/licenses/by/4.0/.

\section{References}

1. Majounie E, Renton AE, Mok K, Dopper EG, Waite A, Rollinson S, Chio A, Restagno G, Nicolaou N, Simon-Sanchez J, van Swieten JC, Abramzon Y, Johnson JO, Sendtner M, Pamphlett R, Orrell RW, Mead S, Sidle KC, Houlden H, Rohrer JD, Morrison KE, Pall H, Talbot K, Ansorge O, Chromosome ALSFTDC, French Research Network on FFA, Consortium I, Hernandez DG, Arepalli S, Sabatelli M, Mora G, Corbo M, Giannini F, Calvo A, Englund E, Borghero G, Floris GL, Remes AM, Laaksovirta H, McCluskey L, Trojanowski JQ, Van Deerlin VM, Schellenberg GD, Nalls MA, Drory VE, Lu CS, Yeh TH, Ishiura H, Takahashi Y, Tsuji S, Le Ber I, Brice A, Drepper C, Williams N, Kirby J, Shaw P, Hardy J, Tienari PJ, Heutink P, Morris HR, 
Pickering-Brown S, Traynor BJ (2012) Frequency of the C9orf72 hexanucleotide repeat expansion in patients with amyotrophic lateral sclerosis and frontotemporal dementia: a cross-sectional study. Lancet Neurol 11(4):323-330. https://doi.org/10.1016/ S1474-4422(12)70043-1

2. Renton AE, Majounie E, Waite A, Simon-Sanchez J, Rollinson S, Gibbs JR, Schymick JC, Laaksovirta H, van Swieten JC, Myllykangas L, Kalimo H, Paetau A, Abramzon Y, Remes AM, Kaganovich A, Scholz SW, Duckworth J, Ding J, Harmer DW, Hernandez DG, Johnson JO, Mok K, Ryten M, Trabzuni D, Guerreiro RJ, Orrell RW, Neal J, Murray A, Pearson J, Jansen IE, Sondervan D, Seelaar H, Blake D, Young K, Halliwell N, Callister JB, Toulson G, Richardson A, Gerhard A, Snowden J, Mann D, Neary D, Nalls MA, Peuralinna T, Jansson L, Isoviita VM, Kaivorinne AL, Holtta-Vuori M, Ikonen E, Sulkava R, Benatar M, Wuu J, Chio A, Restagno G, Borghero G, Sabatelli M, Consortium I, Heckerman D, Rogaeva E, Zinman L, Rothstein JD, Sendtner M, Drepper C, Eichler EE, Alkan C, Abdullaev Z, Pack SD, Dutra A, Pak E, Hardy J, Singleton A, Williams NM, Heutink P, Pickering-Brown S, Morris HR, Tienari PJ, Traynor BJ (2011) A hexanucleotide repeat expansion in C9ORF72 is the cause of chromosome 9p21-linked ALS-FTD. Neuron 72(2):257-268. https://doi.org/10.1016/j.neuron.2011.09.010

3. Van Langenhove T, van der Zee J, Gijselinck I, Engelborghs S, Vandenberghe R, Vandenbulcke M, De Bleecker J, Sieben A, Versijpt J, Ivanoiu A, Deryck O, Willems C, Dillen L, Philtjens S, Maes G, Baumer V, Van Den Broeck M, Mattheijssens M, Peeters K, Martin JJ, Michotte A, Santens P, De Jonghe P, Cras P, De Deyn PP, Cruts M, Van Broeckhoven C (2013) Distinct clinical characteristics of $\mathrm{C} 9$ orf72 expansion carriers compared with GRN, MAPT, and nonmutation carriers in a Flanders-Belgian FTLD cohort. JAMA Neurol 70(3):365-373. https://doi. org/10.1001/2013.jamaneurol.181

4. Arai T, Hasegawa M, Akiyama H, Ikeda K, Nonaka T, Mori H, Mann D, Tsuchiya K, Yoshida M, Hashizume Y, Oda T (2006) TDP-43 is a component of ubiquitin-positive tau-negative inclusions in frontotemporal lobar degeneration and amyotrophic lateral sclerosis. Biochem Biophys Res Commun 351(3):602-611. https://doi.org/10.1016/j.bbrc.2006.10.093

5. Neumann M, Sampathu DM, Kwong LK, Truax AC, Micsenyi MC, Chou TT, Bruce J, Schuck T, Grossman M, Clark CM, McCluskey LF, Miller BL, Masliah E, Mackenzie IR, Feldman H, Feiden W, Kretzschmar HA, Trojanowski JQ, Lee VMY (2006) Ubiquitinated TDP-43 in frontotemporal lobar degeneration and amyotrophic lateral sclerosis. Science 314(5796):130-133. https ://doi.org/10.1126/science. 1134108

6. Ling SC, Polymenidou M, Cleveland DW (2013) Converging mechanisms in ALS and FTD: disrupted RNA and protein homeostasis. Neuron 79(3):416-438. https://doi.org/10.1016/j.neuro n.2013.07.033

7. Ringholz GM, Appel SH, Bradshaw M, Cooke NA, Mosnik DM, Schulz PE (2005) Prevalence and patterns of cognitive impairment in sporadic ALS. Neurology 65(4):586-590. https://doi. org/10.1212/01.wnl.0000172911.39167.b6

8. Wheaton MW, Salamone AR, Mosnik DM, McDonald RO, Appel SH, Schmolck HI, Ringholz GM, Schulz PE (2007) Cognitive impairment in familial ALS. Neurology 69(14):1411-1417. https ://doi.org/10.1212/01.wnl.0000277422.11236.2c

9. Chio A, Vignola A, Mastro E, Giudici AD, Iazzolino B, Calvo A, Moglia C, Montuschi A (2010) Neurobehavioral symptoms in ALS are negatively related to caregivers' burden and quality of life. Eur J Neurol 17(10):1298-1303. https://doi.org/10.111 1/j.1468-1331.2010.03016.x

10. Robberecht W, Philips T (2013) The changing scene of amyotrophic lateral sclerosis. Nat Rev Neurosci 14(4):248-264. https ://doi.org/10.1038/nrn3430
11. Burrell JR, Kiernan MC, Vucic S, Hodges JR (2011) Motor neuron dysfunction in frontotemporal dementia. Brain 134(Pt 9):2582-2594. https://doi.org/10.1093/brain/awr195

12. Van Langenhove T, Piguet O, Burrell JR, Leyton C, Foxe D, Abela M, Bartley L, Kim WS, Jary E, Huang Y, Dobson-Stone C, Kwok JB, Halliday GM, Hodges JR (2017) Predicting development of amyotrophic lateral sclerosis in frontotemporal dementia. J Alzheimers Dis 58(1):163-170. https://doi.org/10.3233/JAD-161272

13. Miller RG, Mitchell JD, Moore DH (2012) Riluzole for amyotrophic lateral sclerosis (ALS)/motor neuron disease (MND). Cochrane Database Syst Rev 3:CD001447. https://doi. org/10.1002/14651858.CD001447.pub3

14. Abe K, Itoyama Y, Sobue G, Tsuji S, Aoki M, Doyu M, Hamada C, Kondo K, Yoneoka T, Akimoto M, Yoshino H, Edaravone ALSSG (2014) Confirmatory double-blind, parallel-group, placebo-controlled study of efficacy and safety of edaravone (MCI-186) in amyotrophic lateral sclerosis patients. Amyotroph Lateral Scler Frontotemp Degener 15(7-8):610-617. https://doi. org/10.3109/21678421.2014.959024

15. The Writing Group on behalf of the Edaravone (MCI-186) ALS Study Group (2017) Safety and efficacy of edaravone in well defined patients with amyotrophic lateral sclerosis: a randomised, double-blind, placebo-controlled trial. Lancet Neurol 16(7):505-512. https://doi.org/10.1016/S1474-4422(17)30115 $-1$

16. Murley AG, Rowe JB (2018) Neurotransmitter deficits from frontotemporal lobar degeneration. Brain 141(5):1263-1285. https:// doi.org/10.1093/brain/awx327

17. Sjogren M, Minthon L, Passant U, Blennow K, Wallin A (1998) Decreased monoamine metabolites in frontotemporal dementia and Alzheimer's disease. Neurobiol Aging 19(5):379-384

18. Engelborghs S, Vloeberghs E, Le Bastard N, Van Buggenhout M, Marien P, Somers N, Nagels G, Pickut BA, De Deyn PP (2008) The dopaminergic neurotransmitter system is associated with aggression and agitation in frontotemporal dementia. Neurochem Int 52(6): 1052-1060. https://doi.org/10.1016/j.neuint.2007.10.018

19. Janssens J, Vermeiren Y, Fransen E, Aerts T, Van Dam D, Engelborghs S, De Deyn PP (2018) Cerebrospinal fluid and serum MHPG improve Alzheimer's disease versus dementia with Lewy bodies differential diagnosis. Alzheimers Dement (Amst) 10:172181. https://doi.org/10.1016/j.dadm.2018.01.002

20. Heng B, Lim CK, Lovejoy DB, Bessede A, Gluch L, Guillemin GJ (2016) Understanding the role of the kynurenine pathway in human breast cancer immunobiology. Oncotarget 7(6):6506-6520. https://doi.org/10.18632/oncotarget.6467

21. Sordillo PP, Sordillo LA, Helson L (2017) The kynurenine pathway: a primary resistance mechanism in patients with glioblastoma. Anticancer Res 37(5):2159-2171. https://doi.org/10.21873 /anticanres. 11551

22. Routy JP, Mehraj V, Vyboh K, Cao W, Kema I, Jenabian MA (2015) Clinical relevance of kynurenine pathway in HIV/AIDS: an immune checkpoint at the crossroads of metabolism and inflammation. AIDS Rev 17(2):96-106

23. Chen Y, Stankovic R, Cullen KM, Meininger V, Garner B, Coggan S, Grant R, Brew BJ, Guillemin GJ (2010) The kynurenine pathway and inflammation in amyotrophic lateral sclerosis. Neurotox Res 18(2):132-142. https://doi.org/10.1007/s12640-009-9129-7

24. Tan L, Yu JT, Tan L (2012) The kynurenine pathway in neurodegenerative diseases: mechanistic and therapeutic considerations. J Neurol Sci 323(1-2):1-8. https://doi.org/10.1016/j. jns.2012.08.005

25. Maddison DC, Giorgini F (2015) The kynurenine pathway and neurodegenerative disease. Semin Cell Dev Biol 40:134-141. https://doi.org/10.1016/j.semcdb.2015.03.002 
26. Ilzecka J, Kocki T, Stelmasiak Z, Turski WA (2003) Endogenous protectant kynurenic acid in amyotrophic lateral sclerosis. Acta Neurol Scand 107(6):412-418

27. Neary D, Snowden JS, Gustafson L, Passant U, Stuss D, Black S, Freedman M, Kertesz A, Robert PH, Albert M, Boone K, Miller BL, Cummings J, Benson DF (1998) Frontotemporal lobar degeneration: a consensus on clinical diagnostic criteria. Neurology 51(6):1546-1554. https://doi.org/10.1212/wnl.51.6.1546

28. Brooks BR, Miller RG, Swash M, Munsat TL, World Federation of Neurology Research Group on Motor Neuron D (2000) El Escorial revisited: revised criteria for the diagnosis of amyotrophic lateral sclerosis. Amyotroph Lateral Scler Other Motor Neuron Disord 1(5):293-299

29. Vermeiren Y, Janssens J, Aerts T, Martin JJ, Sieben A, Van Dam D, De Deyn PP (2016) Brain serotonergic and noradrenergic deficiencies in behavioral variant frontotemporal dementia compared to early-onset Alzheimer's disease. J Alzheimers Dis 53(3):1079_ 1096. https://doi.org/10.3233/JAD-160320

30. Vermeiren Y, Van Dam D, Aerts T, Engelborghs S, Martin JJ, De Deyn PP (2015) The monoaminergic footprint of depression and psychosis in dementia with Lewy bodies compared to Alzheimer's disease. Alzheimers Res Ther 7(1):7. https://doi.org/10.1186/ s13195-014-0090-1

31. Engelborghs S, De Vreese K, Van de Casteele T, Vanderstichele H, Van Everbroeck B, Cras P, Martin JJ, Vanmechelen E, De Deyn PP (2008) Diagnostic performance of a CSF-biomarker panel in autopsy-confirmed dementia. Neurobiol Aging 29(8):1143-1159. https://doi.org/10.1016/j.neurobiolaging.2007.02.016

32. Van Dam D, Vermeiren Y, Aerts T, De Deyn PP (2014) Novel and sensitive reversed-phase high-pressure liquid chromatography method with electrochemical detection for the simultaneous and fast determination of eight biogenic amines and metabolites in human brain tissue. J Chromatogr A 1353:28-39. https://doi. org/10.1016/j.chroma.2014.05.004

33. Meinitzer A, Tomaschitz A, Pilz S, Truber M, Zechner G, Gaksch M, Prietl B, Treiber G, Schwarz M, Baranyi A (2014) Development of a liquid chromatography-mass spectrometry method for the determination of the neurotoxic quinolinic acid in human serum. Clin Chim Acta 436:268-272. https://doi.org/10.1016/j. cca.2014.06.010

34. Schrocksnadel K, Wirleitner B, Winkler C, Fuchs D (2006) Monitoring tryptophan metabolism in chronic immune activation. Clin Chim Acta 364(1-2):82-90. https://doi.org/10.1016/j. cca.2005.06.013

35. Ciorba MA (2013) Kynurenine pathway metabolites: relevant to vitamin B-6 deficiency and beyond. Am J Clin Nutr 98(4):863864. https://doi.org/10.3945/ajcn.113.072025

36. Frisoni GB, Pizzolato G, Bianchetti A, Chierichetti F, Ferlin G, Battistin L, Trabucchi M (1994) Single photon emission computed tomography with [99Tc]-HM-PAO and [123I]-IBZM in Alzheimer's disease and dementia of frontal type: preliminary results. Acta Neurol Scand 89(3):199-203

37. Rinne JO, Laine M, Kaasinen V, Norvasuo-Heila MK, Nagren K, Helenius H (2002) Striatal dopamine transporter and extrapyramidal symptoms in frontotemporal dementia. Neurology 58(10):1489-1493. https://doi.org/10.1212/wnl.58.10.1489

38. Borasio GD, Linke R, Schwarz J, Schlamp V, Abel A, Mozley PD, Tatsch K (1998) Dopaminergic deficit in amyotrophic lateral sclerosis assessed with [I-123] IPT single photon emission computed tomography. J Neurol Neurosurg Psychiatry 65(2):263-265. https://doi.org/10.1136/jnnp.65.2.263

39. Goldstein DS, Holmes C, Sharabi Y (2012) Cerebrospinal fluid biomarkers of central catecholamine deficiency in Parkinson's disease and other synucleinopathies. Brain 135(Pt 6):1900-1913. https://doi.org/10.1093/brain/aws055

40. Goldstein DS, Holmes C, Lopez GJ, Wu T, Sharabi Y (2018) Cerebrospinal fluid biomarkers of central dopamine deficiency predict Parkinson's disease. Parkinsonism Relat Disord 50:108-112. https ://doi.org/10.1016/j.parkreldis.2018.02.023

41. Andersen AD, Blaabjerg M, Binzer M, Kamal A, Thagesen H, Kjaer TW, Stenager E, Gramsbergen JBP (2017) Cerebrospinal fluid levels of catecholamines and its metabolites in Parkinson's disease: effect of 1-DOPA treatment and changes in levodopainduced dyskinesia. J Neurochem 141(4):614-625. https://doi. org/10.1111/jnc. 13997

42. Melamed E, Hefti F, Wurtman RJ (1980) Nonaminergic striatal neurons convert exogenous L-dopa to dopamine in parkinsonism. Ann Neurol 8(6):558-563. https://doi.org/10.1002/ana.410080603

43. Rautio J, Kumpulainen H, Heimbach T, Oliyai R, Oh D, Jarvinen T, Savolainen J (2008) Prodrugs: design and clinical applications. Nat Rev Drug Discov 7(3):255-270. https://doi.org/10.1038/nrd24 68

44. Miyazaki K, Ohta Y, Nagai M, Morimoto N, Kurata T, Takehisa Y, Ikeda Y, Matsuura T, Abe K (2011) Disruption of neurovascular unit prior to motor neuron degeneration in amyotrophic lateral sclerosis. J Neurosci Res 89(5):718-728. https://doi.org/10.1002/ jnr.22594

45. Janelidze S, Hertze J, Nagga K, Nilsson K, Nilsson C, Swedish Bio FSG, Wennstrom M, van Westen D, Blennow K, Zetterberg H, Hansson O (2017) Increased blood-brain barrier permeability is associated with dementia and diabetes but not amyloid pathology or APOE genotype. Neurobiol Aging 51:104-112. https://doi. org/10.1016/j.neurobiolaging.2016.11.017

46. Heyes MP, Saito K, Crowley JS, Davis LE, Demitrack MA, Der M, Dilling LA, Elia J, Kruesi MJ, Lackner A et al (1992) Quinolinic acid and kynurenine pathway metabolism in inflammatory and non-inflammatory neurological disease. Brain $115(\mathrm{Pt}$ 5):1249-1273. https://doi.org/10.1093/brain/115.5.1249

47. de Bie J, Guest J, Guillemin GJ, Grant R (2016) Central kynurenine pathway shift with age in women. J Neurochem 136(5):9951003. https://doi.org/10.1111/jnc. 13496

48. Kato S, Oda M, Tanabe H (1993) Diminution of dopaminergic neurons in the substantia nigra of sporadic amyotrophic lateral sclerosis. Neuropathol Appl Neurobiol 19(4):300-304

49. Spillantini MG, Bird TD, Ghetti B (1998) Frontotemporal dementia and Parkinsonism linked to chromosome 17: a new group of tauopathies. Brain Pathol 8(2):387-402

Publisher's Note Springer Nature remains neutral with regard to jurisdictional claims in published maps and institutional affiliations. 